\section{Case Reports in Oncology}

This article is licensed under the Creative Commons Attribution-NonCommercial 4.0 International License (CC BY-NC) (http://www.karger.com/Services/OpenAccessLicense). Usage and distribution for commercial purposes requires written permission.

\title{
latrogenic Iron Overload in an End Stage Renal Disease Patient
}

\author{
Majd M. Aldwairia Mohamed A. Yassin ${ }^{b}$ \\ aDepartment of Internal Medicine/Hamad Medical Corporation, Doha, Qatar; \\ ${ }^{b}$ Department of Medical Oncology, National Center for Cancer Care and Research, \\ Doha, Qatar
}

Keywords
Hemosiderosis $\cdot$ End stage renal disease $\cdot$ Hemodialysis

\section{Abstract}

Iron overload is a common complication in patients with chronic renal failure treated with dialysis prior to the availability of recombinant human erythropoietin therapy. Iron overload was the result of hypoproliferative erythroid marrow function coupled with the need for frequent red blood cell transfusions to manage symptomatic anemia. The repetitive use of intravenous iron with or without the use of red blood cell transfusions also contributed to iron loading and was associated with iron deposition in liver parenchymal and reticuloendothelial cells. Here we report a 56-year-old female with end-stage renal failure who underwent kidney transplant twice and found to have iatrogenic iron overload with excess intravenous iron treated conservatively.

(C) 2020 The Author(s).

Published by S. Karger AG, Basel

\section{Introduction}

Iron overload is a consequence of iron accumulation that exceeds iron loss. Mechanisms that can lead to iron overload can be classified as absorption of excessive amounts of normal dietaryiron (e.g., hemochromatosis and disorders of ineffective erythropoiesis) [1], absorption of excessive amounts of supplemental iron (medicinal iron overload) [2], and repeated erythrocyte transfusion (e.g., hemolytic anemia [3, 4], aplastic anemia, sideroblastic anemia, MDS, 
Aldwairi/Yassin: Iatrogenic Iron Overload and End Stage Renal Failure

and acute leukemia [5]). In some disorders, more than one mechanism might contribute to the development of iron overload, e.g., iron overload in thalassemia patients can be due to ineffective erythropoiesis and repeated blood transfusions [6]. We describe a patient who developed iron overload with a background of anemia secondary to end stage renal disease (ESRD), for which she received multiple intravenous iron doses.

\section{Case Presentation}

A 56-year-old female with a history of kidney transplantation at 2 times (first 2002, second 2017), referred to the hematology clinic due to persistently elevated ferritin level with the impression of iron overload (iatrogenic).

She has multiple medical problems for which she is being treated or was treated in the past, which includes a history of breast cancer that was treated surgically and with chemotherapy (and tamoxifen), diabetes mellitus, hypertension, and herpes zoster infection that was complicated by post-herpetic neuralgia.

Clinically the patient did not complain of symptoms that can be attributed to organ dysfunction that is related to iron overload. Her laboratory workup showed: ferritin: 1,219.0 $\mu \mathrm{g} / \mathrm{L}$ (persistently above $500 \mu \mathrm{g} / \mathrm{L}$ for 4 years), serum iron: $14 \mu \mathrm{mol} / \mathrm{L}$, TIBC: 50 $\mu \mathrm{mol} / \mathrm{L}$, iron saturation: $28 \%$, ALT: $11.7 \mathrm{U} / \mathrm{L}, \mathrm{AST}: 12 \mathrm{U} / \mathrm{L}$, alkaline phosphatase: $78.0 \mathrm{U} / \mathrm{L}$, total bilirubin: $4.0 \mu \mathrm{mol} / \mathrm{L}$, serum albumin: $35.5 \mathrm{~g} / \mathrm{L}$, INR: 1.0 . The patient was offered MRI of the liver to measure liver iron concentration (LIC); however, she refused to get it performed.

\section{Discussion}

Iron overload used to be considered rare in hemodialysis patients, especially currently where erythropoiesis-stimulating agents are regularly used to manage anemia in hemodialysis patients [6]. However, treatment with these agents can lead to functional iron deficiency, which necessitates iron supplementation [7].

Excessive iron infusions can lead to increased mortality and cardiovascular events in hemodialysis patients, these effects of iron supplementation can be attributed to the increased oxidative stress and induction of mononuclear cell adhesion to endothelial cells, which is an important step in the pathogenesis of atherosclerosis [8]. The risks of cerebrovascular and cardiovascular disease, infection, and hospitalization were significantly higher among patients who were treated with high weekly doses of intravenous iron compared with no intravenous iron [9].

The liver is the main iron storage site and the LIC gives a very accurate picture of total body iron stores in patients with secondary hemosiderosis such as thalassemia major [2].

Excess iron may be deposited in the liver, heart, and endocrine organs, which can lead to liver cirrhosis, heart failure, and several endocrinopathies [10-14].

As with other etiologies of liver cirrhosis (e.g., alcoholic liver disease, viral hepatitis, and NASH) development of liver cirrhosis due to iron deposition takes many years, and with the observed short life span of ESRD patients, it may account for scarcity of iron overload-induced cirrhosis in this population. Keeping this in mind, increased LIC in dialysis patients can be utilized to predict and assess patients with possible iron overload rather than the development of liver cirrhosis or other clinical consequences of iron overload [15].

Among transfusion-dependent thalassemia major patients, it is observed that they have a higher incidence of primary hypothyroidism with a frequency that varies between different 
reports, and it ranges from 4 to 29\%, based on the level of FT4/T4 and TSH. A lower prevalence of hypothyroidism is found among patients with lower iron load, as measured by ferritin levels [16].

A study that investigated endocrinopathies in patients with $\beta$-thalassemia intermedia grouped the patients as non-transfused versus infrequently transfused patients.

The mainstay of iron overload treatment is phlebotomy in non-anemic patients and iron chelation therapy in anemic patients. The challenge in hemodialysis patients with iron overload is that they are anemic and the use of iron with the available iron chelators is generally contraindicated in ESRD/hemodialysis patients. Currently there are three commercially available iron chelators, deferoxamine, deferiprone, and deferasirox [17].

\section{Conclusion}

Intravenous iron in patients with end stage renal failure should be used judiciously and should be monitored by serum ferritin and preferably LIC by MRI to avoid iatrogenic iron overload.

\section{Acknowledgement}

The authors would like to acknowledge Qatar National Library for supporting this publication and the Internal Medicine Residency Program at Hamad Medical Corporation for scientific support.

\section{Statement of Ethics}

Written informed consent was obtained from the patients to allow the publication of information including images. The case report was approved by the Hamad Medical Corporation Medical Research Center.

\section{Conflict of Interest Statement}

The authors report no conflicts of interest regarding this work.

\section{Funding Sources}

The case report was funded by Qatar National Library.

\section{Author Contributions}

M.M. Aldwairi wrote first draft and approved final, M.A. Yassin approved the final draft as well as editing, both authors contributed equally. 
Aldwairi/Yassin: latrogenic Iron Overload and End Stage Renal Failure

\section{References}

1 Yassin MA, MBBS, MSc, CABM, FACP, Soliman AT, MDFRCP PhD, Desanctis V, MD, Abusamaan S, MD, Elsotouhy A, MD, Aldewik N, MSc PhD. Hereditary hemochromatosis in an adult due to H63D mutation: the value of estimating iron deposition by MRI T2* and dissociation between serum ferritin concentration and hepatic iron overload. Blood. 2014;124(21):4891.

2 Yassin M, Soliman AT, De Sanctis V, Moustafa A, Samaan SA, Nashwan A. A young adult with unintended acute intravenous iron intoxication treated with oral chelation: the use of liver ferriscan for diagnosing and monitoring tissue iron load. Mediterr J Hematol Infect Dis. 2017;9(1):e2017008.

3 Kanbour I, Chandra P, Soliman A, De Sanctis V, Nashwan A, Abusamaan S, et al . Severe Liver Iron Concentrations (LIC) in 24 Patients with $\beta$-Thalassemia Major: Correlations with Serum Ferritin, Liver Enzymes and Endocrine Complications. Mediterr J Hematol Infect Dis. 2018;10(1):e2018062.

4 Yassin M, Soliman A, De Sanctis V, Nashwan A, Abusamaan S, Moustafa A, et al . Liver iron content (LIC) in adults with sickle cell disease (SCD): correlation with serum ferritin and liver enzymes concentrations in trasfusion dependent (TD-SCD) and non-transfusion dependent (NT-SCD) patients. Mediterr J Hematol Infect Dis. 2017;9(1):e2017037.

5 Yassin MA, Soliman A, De Sanctis V, Hmissi SM, Abdulla MAJ, Ekeibed Y, et al . The impact of iron overload in patients with acute leukemia and myelodysplastic syndrome on hepatic and endocrine functions. Acta Biomed. 2018;89(3-S):18-22.

6 Eschbach JW, Egrie JC, Downing MR, Browne JK, Adamson JW. Correction of the anemia of end-stage renal disease with recombinant human erythropoietin. Results of a combined phase I and II clinical trial. N Engl J Med. 1987 Jan 8;316(2):73-8.

7 Rostoker G, Vaziri ND, Fishbane S. Iatrogenic Iron Overload in Dialysis Patients at the Beginning of the 21st Century. Drugs. 2016;76(7):741-57.

8 Rostoker G, Vaziri ND. Iatrogenic iron overload and its potential consequences in patients on hemodialysis. Presse Med. 2017;46(12 Pt 2):e312-28.

9 De Sanctis V, Soliman AT, Canatan D, Yassin MA, Daar S, Elsedfy H, Di Maio S, Raiola G, Corrons JV, Kattamis C. Thyroid Disorders in Homozygous $\beta$-Thalassemia: Current Knowledge, Emerging Issues and Open Problems. Mediterr J Hematol Infect Dis. 2019 May 1;11(1):e2019029.

10 Yassin MA, Soliman AT, De Sanctis V, Yassin KS, Abdulla MA. Final Height and Endocrine Complications in Patients with $\beta$-Thalassemia Intermedia: Our Experience in Non-Transfused Versus Infrequently Transfused Patients and Correlations with Liver Iron Content. Mediterr J Hematol Infect Dis. 2019;11(1):e2019026.

11 De Sanctis V, Soliman AT, Candini G, Yassin M, Raiola G, Galati MC, et al . Insulin-like growth factor-1 (IGF-1): Demographic, clinical and laboratory data in 120 consecutive adult patients with thalassaemia major. Mediterr J Hematol Infect Dis. 2014;6(1):e2014074.

12 De Sanctis V, Soliman A, Candini G, Campisi S, Anastasi S, Iassin M. High prevalence of central hypothyroidism in adult patients with $\beta$-thalassemia major. Georgian Med News. 2013 Sep;(222):88-94.

13 De Sanctis V, Elsedfy H, Soliman AT, Elhakim IZ, Pepe A, Kattamis C, et al . Acquired hypogonadotropic hypogonadism $(\mathrm{AHH})$ in thalassaemia major patients: an underdiagnosed condition? Mediterr J Hematol Infect Dis. 2016;8(1):e2016001.

14 Soliman AT, Yassin M, Majuid NM, Sabt A, Abdulrahman MO, De Sanctis V. Cortisol response to low dose versus standard dose (back-to-back) adrenocorticotrophic stimulation tests in children and young adults with thalassemia major. Indian J Endocrinol Metab. 2013 Nov;17(6):1046-52.

15 Kuo KL, Hung SC, Lin YP, Tang CF, Lee TS, Lin CP, et al . Intravenous ferric chloride hexahydrate supplementation induced endothelial dysfunction and increased cardiovascular risk among hemodialysis patients. PLoS One. 2012;7(12):e50295.

16 Kuragano T, Matsumura O, Matsuda A, Hara T, Kiyomoto H, Murata T, et al. Association between hemoglobin variability, serum ferritin levels, and adverse events/mortality in maintenance hemodialysis patients. Kidney Int. 2014 Oct 1;86(4):845-54.

17 Yassin MA, Soliman AT, De Sanctis V, Hussein RM, Al-Okka R, Kassem N, et al. Jadenu® substituting Exjade® in iron overloaded $\beta$-thalassemia major (BTM) patients: a preliminary report of the effects on the tolerability, serum ferritin level, liver iron concentration and biochemical profiles. Mediterr J Hematol Infect Dis. 2018; 10(1):e2018064. 